\title{
Isolation and antibiotic susceptibility profile of Vibrio cholerae isolated from catfish (Pangasius hypophthalmus)
}

\author{
${ }^{1}$ Norshafawati, R., ${ }^{3 *}$ Noorlis, A., ${ }^{1}$ Kuan, C.H., ${ }^{1}$ New, C.Y., ${ }^{4}$ Mingkwan, Y., \\ ${ }^{5}$ Nakaguchi, Y., ${ }^{6}$ Nishibuchi, M. and ${ }^{1,2}$ Son, R. \\ ${ }^{1}$ Department of Food Science, Faculty of Food Science and Technology, \\ Universiti Putra Malaysia, 43400 UPM Serdang, Selangor Darul Ehsan, Malaysia \\ ${ }^{2}$ Food Safety and Food Integrity, Institute of Tropical Agriculture and Food Security, \\ Universiti Putra Malaysia 34300 Serdang, Selangor, Malaysia \\ ${ }^{3}$ Department of Biology, Faculty of Applied Sciences, Universiti Teknologi MARA (UiTM), \\ Negeri Sembilan, 72000 Kuala Pilah, Negeri Sembilan \\ ${ }^{4}$ Department of Pathology, Faculty of Medicine, Prince of Songkla University, Hat Yai, Songkla, \\ 90110 Thailand \\ ${ }^{5}$ Faculty of Bioresources and Environmental Sciences, Ishikawa Prefectural University, Nonoichi \\ City, Ishikawa Prefecture, Japan \\ ${ }^{6}$ Centre for South Asia Studies, Kyoto University, 46 Shomoadachi-cho, Yoshida Sakyo-ku, \\ Kyoto 606-8510, Japan
}

\author{
Article history: \\ Received : 27 January 2017 \\ Received in revised form: \\ 13 February 2017 \\ Accepted: 13 February 2017 \\ Available Online: \\ 18 February 2017
}

\section{Keywords:}

Vibrio cholerae

catfish

antibiotic resistance

\section{DOI:}

http://doi.org/10.26656/ fr.2017.1.004

\begin{abstract}
To date, cholera has cycle the world seven times through the seven pandemic cycles that has affected tens of millions of people. The objective of this study was to determine the presence and density as well as the antibiotic resistance profile of Vibrio cholerae isolated from catfish (Pangasius hypohthalamus). From the combination of the Most Probable Number-Polymerase Chain Reaction-plating on TCBS agar methods, V. cholerae was detected in 32 samples and $V$. cholerae $\mathrm{O} 139$ was detected in 7 samples, with a density ranging between $<3.0$ to 75.0 MPN/g and $<3.0$ to $9.3 \mathrm{MPN} / \mathrm{g}$ respectively. The results obtained in this study indicate that $V$. cholerae will continue to be a major healthcare burden, as the pathogen can be transferred from the aquatic environment to the catfish and the consumption of catfish by humans will present a route of exposure to $V$. cholerae. Proliferation of antibiotic and multiantibiotic resistant bacteria is a public health threat worldwide. Results of antimicrobial susceptibility investigation of $V$. cholerae isolates collected from catfish reported in this study will establish an important baseline data. All the $V$. cholerae isolates were multiantibiotic resistant towards the ten antibiotics tested, including 6 isolates that were resistant to all ten antibiotics and 38 antibiotic resistance patterns. The MAR index values of 0.2 to 1.0 indicate that the isolates were exposed to high risk sources in the environment. Taken together, the information on the prevalence and antibiotic resistance of $V$. cholerae indicate that catfish consumption presents a potential risk to human health and highlight the need for ongoing epidemiological and antimicrobial resistance surveillance.
\end{abstract}

\section{Introduction}

Vibriosis is caused by bacteria belonging to the genus Vibrio, and it is one of the most prevalent infectious diseases in fish and shellfish species, cultivated in marine and estuarine environments (Woo and Bruno, 2011). Various studies have been carried out on seafood and findings concerning the distribution of pathogenic Vibrio in shellfish and fish are well documented (Gopal et al., 2005; Roque et al., 2009; Terzi et al., 2009; Collin and Rehnstam-Holm, 2011; Yu et al., 2013). In China, freshwater catfish, such as yellow catfish (Pelteobagrus fulvidraco); southern catfish (Silurus soldatovi meridionalis,
Chen); Zhengchuan catfish (Silurus soldatovi meridionalis, Chen $\hat{\sigma} \times$ Silurus asotus +); brown bullhead catfish (Ictalurus nebulosus); and channel catfish (Ictalurus punctatus), are the most widely cultured catfish. However, in Malaysia the Pangasius hypohthalamus is more commonly sold in the market. As a tropical country, Malaysia is a favourable environment for the growth of Vibrio spp., but most people are unaware of the potential danger of Vibrio infection associated with consumption of catfish as well as the infection due to finning injury, typically during occupational or accidental exposure while handling the catfish. To underscore this hazard, our report here described the detection and quantification of Vibrio cholerae in catfish. 
Efforts to detect Vibrio species of public health concern in various types of food samples have met with various degrees of success due to the availability of various culture-based and culture-independent methods. Vibrio spp. are known worldwide as virulent pathogens that can quickly cause necrotising soft-tissue infection and life threatening bacteraemia in people with underlying chronic disease. Today, the society is put in danger similar to the pre-antibiotic era due to the worldwide incidences and increased of bacterial resistance to antimicrobial therapy over the past decade. The World Alliance against Antibiotic Resistance (WAAR) has painted a bleak scenario in which the antibiotics being used now may lose their effectiveness over the next few years due to a combination of both used in medication as well as in agricultural practices, leading to the emergence of resistant bacterial strains. Therefore, the need to monitor the multiple antibiotic resistance among various pathogenic bacteria becomes the utmost importance to protect and promote global public health. This study focused on the detection and the determination of antibiotic resistance among Vibrio cholerae isolated from catfish.

\section{Materials and methods}

\subsection{Sampling}

A total of 100 catfish samples were randomly purchased from local supermarkets in Serdang, Selangor, Malaysia. They were transported immediately to the laboratory and analysed upon arrival.

\subsection{Most probable number (MPN) procedure}

The MPN procedure described by Bacteriological Analytical Manual was employed with modifications (Kaysner and DePaola, 2004). Briefly, 25 g portion of the sample was weighed approximately into a sterile stomacher bag and plunged with $225 \mathrm{ml}$ of Tryptic Soy Broth (TSB) (Bacto ${ }^{\mathrm{TM}}$, France) with 1\% NaCl (Merck, Germany) and blended in a stomacher for one minute. The stomached mixture was diluted tenfold for three successive times, and pre-enriched at $37^{\circ} \mathrm{C}$ for 18 to 24 hours prior to MPN analysis. For MPN analysis, $1 \mathrm{ml}$ of each dilution tube was transferred into three tubes set containing $9 \mathrm{ml}$ of APW and further incubated at $37^{\circ} \mathrm{C}$ for 18 to 24 hours. After the incubation period, turbid MPN tubes were then streaked onto Thiosulphate Citrate Bile Salt Sucrose (TCBS) agar (Merck, Germany). Presumptive flat yellow colonies on TCBS agar plates were picked and confirmed by Polymerase Chain Reaction (PCR).

\subsection{DNA extraction and PCR assay}

A well isolated colony was transferred to $2 \mathrm{ml}$ of TSB with $1 \%$ sodium chloride $(\mathrm{NaCl})$ and incubated overnight in an incubator shaker. A $1 \mathrm{ml}$ portion of the cultures was centrifuged at $15,000 \times \mathrm{g}$ for $1 \mathrm{~min}$. The pellet was re-suspended in $500 \mu \mathrm{L}$ sterile distilled water and vortexed vigorously. The cell suspension was boiled for $10 \mathrm{~min}$, immediately chilled on ice for $10 \mathrm{~min}$ and centrifuged again at $15,000 \mathrm{x} g$ for $1 \mathrm{~min}$. The supernatant containing crude DNA was transferred into a new $1.5 \mathrm{~mL}$ tube and $5 \mu \mathrm{L}$ was used as DNA template in PCR, using the specific primer pairs and the PCR conditions as described by Hoshino et al. (1998). The PCR product was analysed by electrophoresis on $2 \%$ agarose gel and stained with $0.3 \mu \mathrm{g} / \mathrm{mL}$ ethidium bromide for visualization of the amplicons under UV light gel documentation system (Alpha Imager ${ }^{\circledR}$, Alpha Innotech).

\subsection{Antibiotic susceptibility}

The susceptibilities of $65 \mathrm{~V}$. cholerae isolates to antibiotics were determined via disk diffusion method (Bauer et al., 1966) that is recommended by CLSI (2006). Briefly, a colony was directly suspended into $1 \mathrm{~mL}$ of normal saline inoculum of $0.85 \% \mathrm{NaCl}$, and adjusted to $0.5 \mathrm{McF}$ arland standard. The inoculum was swabbed evenly on MuellerHinton (MH) agar plate (Merck, Germany) using a sterile cotton swab and left to dry for 3-5 min at room temperature. Antibiotic discs were then placed arranged accordingly onto the plate and subsequently incubated at $37^{\circ} \mathrm{C}$ overnight. The inhibition zone was measured, and the results were interpreted based on the CLSI recommendation (CLSI, 2010) M452A. Ten antibiotic discs (Oxoid, UK) were used: Amikacin (Ak 30), Bacitracin (B 10), Ceptazidine (Caz 30), Chloramphenicol (C 30), Erythromycin (E 15), Gentamicin (Cn 10), Kanamycin (K 30), Norfloxacin (Nor 10), Streptomycin (S 10) and Tetracycline (Te 30).

\subsection{Multiple antibiotic resistance index}

MAR index is a useful tool that provides an excellent estimation about the origin of contamination. MAR index is calculated as the ratio of some resistance antibiotics to the total number of antibiotics to which isolates are exposed to (Krumperman, 1983).

\section{Results and discussion}

In many developed and developing countries, incidence of human Vibrio illnesses due to seafood consumption continued to increase over the last decade (CDC, 2010; MMWR, 2014), due to three 
most commonly reported species, Vibrio vulnificus, Vibrio parahaemolyticus and Vibrio cholerae (WHO, 2001; Baker-Austin et al., 2010). Among the 100 catfish samples randomly collected and analysed, 32 samples were positive for $V$. cholerae and 7 samples were positive for $V$. cholerae O139. The density of the $V$. cholerae and $V$. cholerae $\mathrm{O} 139$ in the positive samples ranged between $<3.0$ to $75.0 \mathrm{MPN} / \mathrm{g}$ and $<3.0$ to $9.3 \mathrm{MPN} / \mathrm{g}$, respectively (data not shown). $V$. cholerae is of paramount health significance in human, particularly strains which produce the cholera toxin, belonging to the $\mathrm{O} 1$ serogroup, but non-O1/ O139 serogroup strains may also produce toxins and disease. V. cholerae has been reported in water used to house or transport ornamental fishes, however, $V$. cholerae is rarely reported as a disease agent in fishes and its role as a fish-borne zoonotic is unclear (Reddacliff et al., 1993; Smith et al., 2012).

Despite the epidemiological relevance and the prevalence of $V$. cholerae in aquatic environment, the presence of this human pathogen is not routinely determined in food sources in many developing countries, despite the facts that the transmission pathway of this pathogen has been traced from fish and shellfish products in the developed countries (Ottaviani et al., 2009; Canigral et al., 2010; Scharer et al., 2011). The data obtained in this study indicated that potentially pathogenic Vibrios are present in catfish, a cheaper source of proteins for the lower income group of consumers, though to date, there is a dearth of data concerning the exposure to $V$. cholerae associated with the consumption of catfish in Malaysia. More attention should be given to fishes from aquaculture as the aquatic environment is more supportive to pathogenic bacteria independently of their host than the terrestrial environment, allowing the pathogen to reach high densities around the fishes, which then ingest them or contaminate the fishes during harvesting.

Sixty-five $V$. cholerae isolates were randomly picked from the 37 positive samples were tested for their susceptibility to 10 selected antibiotics. Despite the 7 positive samples detected using PCR assay of the turbid MPN tubes, we were unable to pick any $V$. cholerae $\mathrm{O} 139$ isolates on the TCBS agar. The $65 \mathrm{~V}$. cholerae isolates were found to be resistant to two or more antibiotics, with 6 isolates from different samples showing resistance towards all 10 antibiotics tested and 38 antibiotic resistance patterns (Table 1). According to Krumperman (1983), a multiple antibiotic resistance (MAR) index values of less than or equal to 2.0 is considered to indicate that the bacterial isolates tested originated from animal in which antibiotics are seldom or never used, but
Table 1. Antibiotic susceptibility patterns and multiple antibiotic resistance index of $V$. cholerae isolated from catfish

\begin{tabular}{|c|c|c|}
\hline $\begin{array}{l}\text { Antibiotic resistant } \\
\text { patterns }\end{array}$ & $\begin{array}{l}\text { Multiple antibiotic } \\
\text { resistance index } \\
\text { (MAR) }\end{array}$ & No. Isolates \\
\hline EB & 0.2 & 1 \\
\hline KB & 0.2 & 2 \\
\hline TeEB & 0.3 & 5 \\
\hline AkEB & 0.3 & 1 \\
\hline CazEB & 0.3 & 1 \\
\hline TeCazB & 0.3 & 2 \\
\hline NorCnEB & 0.4 & 2 \\
\hline TeAkEB & 0.4 & 6 \\
\hline TeCazEB & 0.4 & 1 \\
\hline TeCEB & 0.4 & 2 \\
\hline TeEKB & 0.4 & 1 \\
\hline TeSEB & 0.4 & 1 \\
\hline CSAkEB & 0.5 & 1 \\
\hline NorCnSKB & 0.5 & 2 \\
\hline NorTeSEB & 0.5 & 2 \\
\hline SCazAkEB & 0.5 & 2 \\
\hline TeAkEKB & 0.5 & 1 \\
\hline TeCSEB & 0.5 & 1 \\
\hline TeSAkEB & 0.5 & 4 \\
\hline TeSCazEB & 0.5 & 1 \\
\hline CnCSEKB & 0.6 & 1 \\
\hline CnTeSAkEB & 0.6 & 1 \\
\hline TeCCazAkEB & 0.6 & 1 \\
\hline TeSAkEKB & 0.6 & 2 \\
\hline NorTeCazAkEB & 0.6 & 1 \\
\hline CnTeSAkEKB & 0.7 & 1 \\
\hline NorCnSCazAkKB & 0.7 & 2 \\
\hline NorTeSCazAkKB & 0.7 & 1 \\
\hline NorTeSCazEKB & 0.7 & 1 \\
\hline NorCnTeCCazAkB & 0.7 & 1 \\
\hline TeCSAkEKB & 0.7 & 1 \\
\hline TeCSCazAkEB & 0.7 & 2 \\
\hline NorCnCSAkEKB & 0.8 & 1 \\
\hline NorCnTeCSEKB & 0.8 & 1 \\
\hline NorCnTeSAkEKB & 0.8 & 1 \\
\hline TeSEBTeAkEB & 0.8 & 1 \\
\hline NorCnTeSCazAkEKB & 0.9 & 1 \\
\hline NorCnTeCSCazAkEKB & 1.0 & 6 \\
\hline
\end{tabular}

Ak: Amikacin (Ak 30); B: Bacitracin (B 10); Caz: Ceptazidine (Caz 30); C: Chloramphenicol (C 30); E: Erythromycin (E 15); Cn: Gentamicin (Cn 10); K: Kanamycin (K 30); Nor: Norfloxacin (Nor 10); S: Streptomycin (S 10); Te: Tetracycline (Te 30)

a MAR index greater than 2.0 indicates that the bacterial isolates originated from high risk sources where antibiotics are widely used. In 1974, a review of human pathogenic bacteria stated that cultured fish 
have not been considered to be important vectors of disease to the human consumer but is considered as a minor public health threat (Stevenson and Biol, 1970; Ghittino, 1972; Reasoner, 1974). Today, the scenario has changed, as aquaculture, comprising all forms of culture of aquatic animals and plants in fresh, brackish and marine environments has rapidly grown to be the major food producing sector worldwide. The high MAR index values among the $V$. cholerae isolates in this study is of great concern as fish may serve as both passive and active carriers of this human pathogen, which may have been introduced into the aquatic environment through human sewage and other sources of water pollution. In North America, the consumption of raw molluscan shellfish harvested in waters contaminated with raw of poorly treated human sewage has been implicated in the high numbers of fish-associated human illnesses (Bostock et al., 2010).

Antibiotic resistance of $V$. cholerae was presumably due to the over usage of antibiotics and it is no exceptional in aquaculture for disease prevention. Phuong et al. (2005) reported on the bacterial resistance to antibiotics attributed to the usage of antibiotics in catfish farm and nurseries in the Mekong River Delta. Excessive usage of antibiotics exposes the bacteria to high antibiotic pressure which led to the development of antimicrobial resistance genes. Wastewater treatment plants were also highlighted as the most highly potential formation of antimicrobial resistance due to heavy usage of antibiotic that accumulates in the sewage. This is supported by Ben et al. (2017) who stated that municipal wastewater treatment plant (MWTP) effluents represent an important contamination source of antibiotic resistance which threatens the ecological safety of receiving environments. Antimicrobial resistance occurs mainly due to the development of resistance genes or mutation of existing genes being subjected to environmental stresses and antibiotic pressures. It can also be occurred through horizontal gene transfer, mostly involving plasmid transfer between organisms.

The use of antibiotics will continue to increase in large due to the Earth's population is growing with the increasing number of people needing healthcare. In addition, the uncontrollable usage of antibiotics in animal husbandry and aquaculture will potentially induce the growing numbers of antibiotic resistant pathogens and commensal microorganisms. What makes the situation more dramatic is the globalization of pathogens resistance to antibiotics, for example, the spread of KPC (Klebsiella pneumoniae carbapemenase) that synthesizes an enzyme responsible for the degradation of carbapenem antibiotics (Nordmann et al., 2011). What is more alarming is when bacterial resistance is linked with bacterial virulence factors causing severe impact damage if an outbreak occurs.

Nowadays, we have come to accept the fact that our experience of resistance to antimicrobial agents is nearly as old as our experience of the agents themselves. Currently, measures to protect aquaculture animals from pathogenic bacteria without using antibiotics, using a holistic approach involving the pathogen, host and environment are being developed and tested. However, based on our knowledge on the bacterial resistance, a more realistic technique to control pathogenic bacteria would be the application of biocontrol together with a rational use of antibiotics, to make the industry more sustainable and preserve global public health.

\section{Acknowledgements}

Research fund was sponsored by Fundamental Research Grant Projects (FRGS/1/2014/SG05/ UPM/01/2) from the Ministry of Education, Malaysia, in part, by a fund for Research on international cooperation in medical science, Research on global health issues, Health and Labor Science Research Grants, the Ministry of Health, Labor, and Welfare of Japan, and a fund from Kyoto University Research Coordination Alliance, Japan, by a fund by Kakenhi Grant-in-Aid for Scientific Research and from the Japan Society for the Promotion of Sciences.

\section{References}

Baker-Austin, C., Stockley, L., Rangdale, R. and Martinez-Urtaza, J. (2010). Environmental occurrence and clinical impact of Vibrio vulnificus and Vibrio parahaemolyticus: a European perspective. Environmental Microbiology Report, 2, 7-18.

Bauer, A.W., Kirby, W.M.M., Serris, J.C. and Turck, M. (1966). Antibiotic susceptibility testing by a standardized single disc method. American Journal of Clinical Pathology, 45, 493-496.

Bostock, J., McAndrew, B., Richards, R., Jauncey, K., Telfer, T., Lorenzen, K., Little, D., Ross, L., Handaisyde, N., Gatward, I. and Corner, R. (2010). Aquaculture: global status and trends. Philosophical Transactions of the Royal Society B, 365, 2897-2912.

Canigral, L., Moreno, Y., Alonso, J.I., Gonzalez, A. and Ferrus, M.A. (2010). Detection of Vibrio vulnificus in seafood, seawater and wastewater samples from a Mediterranean coastal area. Microbiology Research, $165,657-664$. 
CDC. (2010). Cholera and Other Vibrio Illness Surveillance (COVIS), summary data, 2008. Retrieved January 13, 2017 from CDC website: http://www.cdc.gov/ nationalsurveillance

CLSI. (2010). Methods for Antimicrobial Dilution and Disk Susceptibility Testing of Infrequently Isolated or Fastidious Bacteria; Approved Guideline- Second Edition. CLIS document M45-A2. Wayne, PA: Clinical and Laboratory Standards Institute.

Collin, B. and Rehnstan-Holm, A.S. (2011). Occurrence and potential pathogenesis of Vibrio cholerae, Vibrio parahaemolyticus and Vibrio vulnificus on the south coast of Sweden. FEMS Microbiology Letters, 78, 306-313.

Ghittino, P. (1972). Aquaculture and associated diseases of fish of public health importance. Journal of American Medical and Veterinary Association, 161, 1476-1485.

Gopal, S., Otta, S.K., Kumar, S., Karunasagar, I. and Nishibuchi, M. (2005). The occurrence of Vibrio species in tropical shrimp culture environments; implication for food safety. International Journal of Food Microbiology, 102, 151-159.

Hoshino, K., Yamasaki, S., Mukhopadhya, A. K., Chakraborty, S., Basu, A., Bhattacharya, S. K., Nair, G. B., Shimada, T and Takeda, Y. 1998. Development and evaluation of a multiplex PCR assay for a rapid detection of toxigenic Vibrio cholera 01 and 0139. Immunology and Medical Microbiology, 20, 201-207.

Kaysner, C.A. and DePaola, Jr. A. (2004). Bacteriological Analytical Manual: Vibrio. Retrieved on October 20, 2017 from Food and Drug Administration Website: http://www.fda.gov/Food/FoodScienceResearch/ LaboratoryMethods/ucm070830.htm

Krumperman, P. H. (1983). Multiple Antibiotic Resistance Indexing of Escherichia coli to Identify High-Risk Sources of Fecal Contamination of Food. Applied and Environmental Microbiology, 46, 165-170.

Morbidity, Mortality Weekly Report (MMWR). (2014). Incidence and Trends of Infection with Pathogens Transmitted Commonly Through Food - Foodborne Disease Active Surveillance Network, 10 U.S. Sites, 2006-2013, 63, 328-332.

Nordmann, P., Naas, T. and Poirel, L. (2011). Global spread of carbapenenmase-producing Enterobacteriaceae. Emerging Infectious Disease, 17, 1791-1798.

Ottaviani, D., Leoni, F., Rocchegiani, E., Canonico, C., Santarelli, S.S., Masini, L., Di Trania, V., Canonicoa, C., Planettih, A., Tegac, L. and Carraturo, A. (2009). Prevalence and virulence properties of non-O1 non-O139 Vibrio cholerae strains from seafood and clinical samples collected in Italy. International Journal of Food Microbiology, 132, 47-53.

Phuong, N.T., Oanh, D.T.H., Dung, T.T. and Sinh, L.X. (2005). Bacterial resistance to antimicrobial use in shrimps and fish farm in the Mekong Delta, Vietnam. In Proceeding of the International Workshop on Antibiotic Resistance in Asian Aquaculture Environments, Chiang Mai, Thailand. p. 2-17. ISBN 88-901344-3-7.
Reasoner, D.J. (1974). Microbiology - detection of bacterial pathogens and their occurrence, Journal Water Pollution Control Federation, 46, 1395-1406.

Reddacliff, G.I., Hornitzky, M., Carson, J., Peterson, R. and Zelski, R. (1993). Mortalities of goldfish, Carassius auratus (L.), associated with Vibrio cholerae (non-01) infection. Journal of Fish Diseases, 16, 517-520.

Roque, A., Lopez-Joven, C., Lacuesta, B., Elandaloussi, I., Wagley, S., Furones, M.D., Ruiz-Zarzuela, I., de Blas, L., Rangdale, R. and Gomez-Gil, B. (2009). Detection and identification of $t d h$ - and trh-positive Vibrio parahaemolyticus strains from four species of cultured bivalve molluscs on the Sapnish Mediterranean coast. Applied and Environmental Microbiology, 75, 75747577.

Scharer, K., Savioz, S., Cernela, N., Saegesser, G. and Stephen, R. 2011. Occurrence of Vibrio spp. in fish and shellfish collected from the Swiss Market. Journal of Food Protection, 74, 1345-1347.

Smith, K.F., Schmidt, V., Rosen, G.E. and Amaral-Zettler, L. (2012). Microbial diversity and potential pathogens in ornamental fish aquarium water. PLOS ONE, 7, e39971.

Stevenson, J.P. and Biol, F.I. (1970). The problems of fish disease. Veterinary Records, 87, 529-531.

Terzi, G., Buyuktanir, O. and Yurdusev, N. (2009). Detection of the $t d h$ and trh genes in Vibrio parahaemolyticus isolates in fish and mussels from Middle Black Sea Coast of Turkey. Letters in Applied Microbiology, 49, 757-763,

Ben, W., Jian, W., Cao, R., Yang, M., Zhang, Y. and Qiang, Z. (2017). Distribution of antibiotic resistance in the effluents of ten municipal wastewater treatment plants in China and the effect of treatment processes. Chemosphere, 172, 392-398

WHO. (2001). Report of the Joint FAO/WHO Expert Consultation on Risk Assessment of Microbiological Hazards in Foods; hazard identification, exposure assessment and hazard characterization of Campylobacter spp. in broiler chickens and Vibrio spp. in seafood. WHO Headquarters, Geneva, Switzerland (23-27 July).

Woo, P.T.K. and Bruno, D.W. (2011). Fish diseases and disorders. Viral, Bacterial and Fungal Infections, vol. 3 . p. 570-605, Wallingford: CABI.

Yu, W.T., Jong, K.J., Lin, Y.R., Tsai, S., Tey, Y.H. and Wong, H.C. (2013). Prevalence of Vibrio parahaemolyticus in oyster and cam culturing environments in Taiwan. International Journal of Food Microbiology, 160, 185-192. 